\title{
O EMPREGO DAS ESTRATÉGIAS DE LEITURA EM TEXTOS DE INGLÊS COMO LE
}

\author{
K. C. N. BRAUER \\ Pontifícia Universidade Católica de São Paulo \\ kcnb76@gmail.com
}

Artigo submetido em julho/2014 e aceito em dezembro/2014

DOI: $10.15628 /$ holos.2014.2213

\section{RESUMO}

O presente artigo analisou o uso de estratégias de leitura em língua estrangeira (LE), mobilizadas por aprendizes do V Semestre do curso de Letras, de uma universidade particular do sul do país, durante um semestre. Este trabalho está sustentado pelos aportes de Oxford (1990), O'Malley e Chamot (1990) no que tange às estratégias de leitura, de Colomer e Camps (2002) no que se refere a compreensão de textos lidos. Damásio (1996) no que se relaciona a emoção. A metodologia utilizada, de natureza qualitativa, incluiu preenchimento de questionários e respostas a exercícios de compreensão e interpretação leitora. Os dados aqui levantados confirmaram a relevância do uso de estratégias de leitura e indicaram aquelas empregadas com mais frequência pelos estudantes investigados, além de evidenciar o recurso reiterado a um dado conjunto de estratégias, tanto de natureza cognitiva, quanto de compensação e metacognitivas. Além disso, indicou a mobilização intensiva da memória, sobretudo através da ativação do conhecimento prévio (memória de longo prazo), efetivando-se, por meio da comparação entre língua materna e língua estrangeira. A pesquisa confirmou a hipótese da facilitação da compreensão leitora a partir do uso de estratégias, do desenvolvimento da consciência linguística, bem como da mudança qualitativa no processo de leitura ao longo de um semestre de estudos. Esta pesquisa destacou a importância do emprego de estratégias de leitura para uma melhor compreensão, o que ocorre sob a influência inevitável da emoção. Os resultados aqui expostos podem ser úteis para a área de Letras e contribuir tanto para o ensino da leitura em LE e língua materna.

PALAVRAS-CHAVE: Estratégias de Leitura, Língua Estrangeira, Emoção.

\section{THE USE OF READING STRATEGIES IN ENGLIH TEXTS AS FOREIGN LANGUAGE}

\begin{abstract}
This article analyzed the use of reading strategies in $\mathrm{FL}$, mobilized by learners of 5 th Language Semester of a private university in the south part of the country, during one semester. It is based on Oxford (1990), O'Malley and Chamot (1990) regarding to the reading strategies, Colomer and Camps (2002) in reference to the understanding of texts read. Damásio (1996) in what is related to the emotion. The methodology was qualitative and included questionnaires and exercises in reading comprehension and interpretation. The data collected confirmed the relevance of the reading strategy use and indicated those strategies used often by the investigated students besides evidencing resource reiterated to a certain strategy set of cognitive, compensation and
\end{abstract}

metacognitive nature. It also indicated the intensive mobilization of memory, especially through activation of prior knowledge, effecting up through the comparison between mother tongue and foreign language. The research confirmed the hypothesis that facilitation of reading comprehension through the use of strategies, of the linguistic awareness development as well as qualitative change in the reading process over a semester of study. It also evidenced the importance of employing reading strategies to better understand what happens under the influence of emotion. The results presented here may be useful mainly to the area of Languages and it can contribute to the teaching of reading a foreign language and mother tongue.

KEYWORDS: Reading Strategies, Foreign Language, Emotion. 


\section{INTRODUÇÃO}

Ler é criar significado, deste modo, o ato de ler está relacionado diretamente à compreensão, uma vez que sem compreensão não há, de fato, leitura. Além disso, todo o gesto de leitura exige uma interação efetiva entre texto e leitor. Como apontam Dell'Isola e Peret (2001, p.37), "Ler é interagir, é construir significado para o texto. Quando se invoca a natureza interativa do tratamento textual, é preciso ter em mente todos os tipos de conhecimento que o leitor utiliza durante a leitura [...]".

Assim, o presente trabalho tem como proposta de pesquisa inter-relacionar compreensão de leitura e uso das estratégias, averiguando quais as mais empregadas por aprendizes de inglês como língua estrangeira, em um ambiente universitário, na disciplina de Língua Inglesa V.

Esta investigação propôs-se, ainda, a comprovar, a ocorrência ou não da compreensão dos textos lidos, discutindo-se a influência da emoção sobre a compreensão leitora. Por fim, salientouse a possibilidade de o aprendiz estar ou não consciente da relevância do uso das estratégias de leitura e as mudanças ocasionadas nos seus procedimentos de leitura ao longo do estudo, fazendose, ademais, uma autocrítica e as considerações finais atinentes ao estudo realizado.

A razão da escolha do assunto desta pesquisa está associada à minha experiência profissional como professora de inglês e português, pois participei de projetos de produção textual e observei a dificuldade dos alunos frente à leitura de textos em uma língua estrangeira (LE). A importância de estudar estratégias de leitura está na razão de auxiliar o aluno a desenvolver a compreensão leitora de uma língua estrangeira.

A maioria dos estudos sobre estratégias de leitura estão preocupados com a escolha e o emprego das estratégias. O proposto estudo pode contribuir com questões que se remetem tanto ao ensino da leitura em língua estrangeira e língua materna, como das demais disciplinas curriculares do ensino fundamental, médio e superior.

Este artigo está sustentado pelos aportes de Oxford (1990), O'Malley e Chamot (1990) no que tange às estratégias de leitura, de Colomer e Camps (2002) no que se refere a compreensão de textos lidos e de Damásio (1996) no ponto relacionado a emoção. Também faz uso de recursos metodológicos de natureza qualitativa como preenchimento de questionários e desenvolvimento de exercícios de compreensão e interpretação leitora para levantar os dados analisados.

Segundo Oxford (1990), com o uso de estratégias, o leitor pode alcançar, além do entendimento, a autonomia na leitura. Oxford (1990, p. 11) acredita que "as estratégias de aprendizagem de uma língua são empregadas porque há um problema a ser resolvido, uma tarefa a ser efetuada, um objetivo a ser encontrado ou uma meta a ser concretizada". Por esta razão as estratégias de leitura foram o foco nesta pesquisa.

\section{LEITURA: ATO E PROCESSO}

Ler é uma habilidade imprescindível e um exercício exigente do intelecto, envolvendo a pessoa e a sociedade em que ela vive. É por meio da ação psicofísica e interativa levada a bom termo via ato de ler que o leitor constrói a significação textual, agregando o conhecimento já existente ao conhecimento que possui sobre a língua e sobre o mundo. Enquanto lê, o indivíduo 
interage com o texto e com pares, ancorando-se na interação leitor-texto e leitor-história e cultura para se desenvolver e adquirir novos conhecimentos.

A construção do significado da leitura acontece de maneira progressiva, porém não linear, e se concretiza de forma pessoal, individual, apesar de a leitura ser uma atividade cultivada socialmente. As alterações no processo de leitura são frequentes e estimulam mudanças cognitivas relevantes para a formação do leitor. Ler é, então, uma atividade complexa, plural, multidirecionada e necessita do engajamento de muitos fatores intelectivos - memória, atenção, percepção e conhecimentos linguísticos, que precisam ser ativados, quando se quer fazer sentido do texto (KLEIMAN,1996).

Conforme Morais (1996, p.12 e 13), indubitavelmente, ler “é uma questão pública. É um meio de aquisição de informação (e a escritura um meio de transmissão de informação), portanto um componente de um ato social. Mas ela constitui também um deleite individual".

Então, ao mesmo tempo, em que a formação leitora implica a interação com outros leitores e com o texto, também propicia a interação do leitor consigo mesmo.

A atividade leitora relaciona-se à interação e à criatividade e não somente à repetição. “Ouvir e ler não são simples manifestações de um uso reprodutivo e passivo da língua. Falar e escrever, ouvir e ler são ações igualmente a seu modo, ativas, produtivas e criativas" (MARCUSCHI, 2005, p.40). Por exemplo, no momento da leitura, o leitor examina as informações obtidas, avaliaas e separa aquelas tidas como prioritárias das demais. O que é retido na mente é o sentido geral do texto, e, no processo, o indivíduo se mobiliza integralmente, assumindo uma postura participativa e atuante.

Para Nunes (2000, p. 107), o leitor é “[...] ativo, ele planeja, decide, coordena habilidades e estratégias, traz para o texto expectativas, informações, ideias crenças, seleciona pistas significativas, formula ou confirma hipóteses". Ele dialoga com o texto. Em outros termos, ler é interagir.

Se o leitor participa do processo de construção do sentido com o escritor, a interação será tanto mais qualificada quanto mais o forem as técnicas interpretativas que fazem parte da habilidade que ele já detém, que é a de se colocar no discurso, ao situar-se no contexto pragmático da linguagem. A leitura, como prática comunicativa é uma atividade envolvente, e, leitores e escritores, como seres inseridos no contexto social, político, cultural e histórico, constroem e desenvolvem conhecimento, enquanto interagem através do texto.

\subsection{Objetivos e leitura}

Definir objetivos previamente é uma forma de ganhar tempo na busca de informação e no processamento de leitura. Diferentes objetivos sugerem e demandam distintas estratégias de abordagem textual. Assim, determinar objetivos antecipadamente ajuda muito, segundo Kleiman (2004), no estabelecimento da coerência do texto. Os objetivos podem ser estipulados de acordo com os tipos de texto e determiná-los também é relevante para a formulação de hipóteses. De outra parte, formular hipóteses viabiliza a tarefa de observação, uma vez que o leitor passa a monitorar seu processo de compreensão, buscando preservar, ao mesmo tempo, o caráter global do texto. Na análise de hipóteses, o leitor confirma algumas e descarta outras, fazendo uma revisão textual que envolve estratégias de leitura. 
Como guia do leitor, os objetivos podem levar o ato de ler à solução de problemas de compreensão, inclusive, relativos à língua, ou seja, ao desenvolvimento da consciência linguística sobre o idioma em que o texto está escrito. Além disso, possibilita o contato com a produção cultural da humanidade e o ingresso pleno no mundo letrado. Para Koch et al. (2008, p.19) "são, pois, os objetivos do leitor que nortearão o modo de leitura, em mais tempo ou em menos tempo; com mais atenção ou com menos atenção; com maior interação ou com menor interação, enfim".

De acordo com Kleiman (2004) existem evidências precisas de que nossa capacidade de processamento e memória melhoram expressivamente quando é fornecido um objetivo para uma tarefa. Também há evidência experimental que mostra que somos capazes de recordar muito melhor aqueles detalhes de um texto ligados a um objetivo.

Intrinsecamente relacionada aos objetivos, existe também a influência da motivação, que se vincula aos sentimentos do leitor em relação à língua escrita. De acordo com Damásio (1996) se ela for apresentada como algo difícil, que desperta uma sensação de impossibilidade de realização da tarefa, a autoimagem ficará baixa e o leitor evitará sistematicamente a tarefa de ler. Porém, com o auxílio de estratégias de leitura e orientações adequadas, a leitura torna-se um desafio e o leitor pode sentir-se mais confiante e motivado.

\subsection{Estratégias de leitura}

As estratégias são mobilizadas, concomitantemente, ao processamento da leitura, possibilitando o seu desenvolvimento, ou a sua alteração de curso. No momento em que o leitor lê um texto, sua mente pode selecionar ou descartar informações, dependendo do grau de importância que a informação considerada tenha para ele e seus objetivos de leitura. Essa seleção decorre do levantamento de hipóteses sobre o significado do texto.

Na ótica de Solé (1998), as estratégias são procedimentos de elevado caráter cognitivo, implicando objetivos a serem atingidos, planejamento das ações que se desencadeiam para atingilos, assim como avaliação e possíveis alterações ou variações do percurso de leitura desenvolvido até então.

Ao usar estratégias de leitura, é fundamental que o estudante saiba que, ao ler, mesmo leitores fluentes encontram certas dificuldades e as eliminam com o auxílio de procedimentos definidos, como a moderação da rapidez da leitura, o aumento da atenção, o uso do conhecimento prévio, a identificação da estrutura textual, a revisão, o autoquestionamento, o uso de resumos e as pistas textuais. Todos esses procedimentos citados podem beneficiar a compreensão textual, são estratégias, em outras palavras, ferramentas, técnicas ou métodos utilizados para obter uma informação, isso é, funcionam como instrumentos facilitadores do processo de compreensão, não havendo uma receita ideal que solucione todas as dificuldades de vez, em definitivo.

A categorização feita por Oxford (1990) distribui-se em dois blocos as estratégias de leitura, que se subdividem em três subgrupos cada. Primeiramente, as estratégias são classificadas em diretas e indiretas. As diretas se subdividem em estratégias de compensação, de memória e cognitivas; por sua vez o grupo de estratégias indiretas classificam-se em afetivas, metacognitivas e sociais.

Estratégias Diretas, conforme Oxford (1990), são citadas a seguir:

- Cognitivas: são as estratégias de entendimento e elaboração de enunciados novos por 
meio da organização e mudança da língua em estudo pelo aprendiz; elas referem-se a operações usadas na resolução de problemas, na síntese e transformação de materiais, por exemplo, textos lidos. Estratégias que podem ser consideradas cognitivas: verificação ou clarificação, inferência por indução, dedução por raciocínio, prática, memorização e monitoração.

- De memória: são as estratégias de armazenamento e recuperação de dados novos.

- De compensação: são as estratégias que ajudam no entendimento e na produção oral ou escrita em uma língua diferente da materna, ainda que haja limitações de conhecimento da língua alvo.

Estratégias Indiretas, tal como vistas pela autora, são elencadas logo em seguida:

- Afetivas: são as estratégias que equilibram motivação, valores, emoção, comportamento. Sociais: são aquelas que propiciam cooperação e interação entre os membros do grupo de estudo; são ferramentas que se comprometem a oportunizar novas chances de adquirir informações, conhecimento.

- Metacognitivas: são as estratégias que visam desenvolver controle, avaliação e planejamento da aprendizagem. Elas são empregadas para equilibrar atividades, analisar e autodirecionar o aprendizado, por exemplo, em leitura. Entre essas estratégias podem-se citar o planejamento, a determinação de metas, a seleção de objetivos de leitura e o automonitoramento.

O'Malley e Chamot (1990) dispuseram uma categorização das estratégias de aprendizagem dividindo-as em três grupos: sócio/afetivas, metacognitivas e cognitivas. Para os autores um excelente expediente seria aproveitar as estratégias metacognitivas em combinação com as cognitivas, pois a inter-relação entre tipos de estratégias distintas apresenta normalmente melhor resultado do que a sua utilização isolada.

É relevante mencionar que algumas dessas estratégias são particularmente adequadas a tarefas que envolvem habilidades linguísticas. Pode-se citar, por exemplo, a compreensão leitora, na qual é muito comum o emprego de estratégias dedutivas. Oxford (1990) desenvolveu trabalho contendo estratégias diversificadas, referentes às habilidades linguísticas: de leitura, fala, escuta e escrita. Sobre as estratégias sociais e afetivas não há muitos estudos, sendo pouco encontradas menções a essas estratégias no estudo de línguas estrangeiras. A razão disso talvez seja ao fato de os estudantes de língua estrangeira não estarem acostumados a darem atenção a seus próprios sentimentos e nem a se arriscarem em relações interpessoais, com a intenção de melhorar seu desempenho linguístico.

Oxford (1990) percebeu, além disso, que quanto mais motivados os aprendizes estão mais estratégias costumam mobilizar, sendo que a razão pela qual estão lendo o texto também os leva a escolher determinadas estratégias de preferência a outras. Outros fatores também acabam influenciando a seleção de estratégias, citando-se, dentre eles, o gênero, o meio de origem, as crenças, a religião, a idade, o tipo de tarefa, o estilo de aprendizagem, além, é claro, das necessidades específicas do leitor.

Além das estratégias, a emoção também está presente no processo de leitura. Deve-se acrescentar, ainda, que a imagem que o leitor tem de si pode interferir na qualidade da leitura, porque cognição e emoção dispõem de redes neurais comuns, essenciais para os atos de perceber, sentir, pensar, entender, lembrar e acionar conhecimentos. Se a memória que o leitor guarda de 
suas práticas leitoras não é prazerosa, essa lembrança poderá afetar seu desempenho, suas expectativas e sua disposição para ler. É relevante, então, que o leitor tenha uma expectativa positiva, pois não há aquisição de memória fora de algum estado emocional. Assim nos aprofundaremos um pouco mais na questão da emoção e leitura.

\subsection{Emoção e leitura}

A respeito da influência da emoção sobre o processo de compreensão, Damásio (1996) assegura que a emoção e a emoção experienciada - o sentimento - são fatores absolutamente imprescindíveis à racionalidade. Em sua ótica, é impossível separar emoção de cognição sem perdas. Para o autor, a inexistência de emoção pode arruinar o raciocínio, uma vez que para decidir, necessariamente, o indivíduo mobiliza a afetividade, não havendo sentido nesse afastamento forçado. $\mathrm{O}$ autor destaca a importância do fator emocional para a cognição e não recomenda que se considere a inferência da emoção sempre em sentido negativo. Dadas às circunstâncias, a relação emoção-razão poderia, então, refletir-se na leitura e sua compreensão e a hipótese é que, de fato, interfere.

Primeiramente, então, é importante definirmos o que seriam emoções. Segundo Damásio (2000, p.74) "são conjuntos complexos de reações químicas e neurais, formando um padrão". Todas as emoções têm alguma função reguladora a desenvolver, levando, de um modo ou de outro, à criação de circunstâncias benéficas para o organismo em que o fenômeno se manifesta; as emoções estão ligadas à vida de um organismo, ao seu corpo, para ser exato, e seu papel é ajudar o organismo a conservar a vida. Além disso, a emoção está ligada diretamente à memória e esta se relaciona à razão, influenciando a tomada de diferentes atitudes frente às escolhas do dia a dia, como aquelas relacionadas ao ato de ler.

Maturana (2005 p. 15) também declara existir um elo muito forte entre emoção e razão, conforme se depreende das palavras que se seguem:

[...] ao nos declararmos seres racionais vivemos uma cultura que desvaloriza as emoções, e não vemos o entrelaçamento cotidiano entre razão e emoção, que constitui nosso viver humano, e não nos damos conta de que todo sistema racional tem um fundamento emocional.

De acordo com Fridja et al. (2000), que também falam sobre a conexão entre aspectos afetivos e cognitivos, existe uma grande influência das emoções sobre as crenças. Esses autores ressaltam que, enquanto o modo racional de pensar não é suficiente para a ação, as emoções influenciam as pessoas a agirem de uma determinada forma, de modo instantâneo. Os sentimentos, por sua vez, influenciam as crenças, e da mesma maneira as crenças atuam sobre os sentimentos.

Por sua vez, Dörnyei e Skehan (2002) se referem à emoção positiva como um estado de motivação e afirmam que a motivação afeta a direção e magnitude do comportamento humano, ou, mais especificamente, a escolha de uma ação particular, a persistência e o esforço despendido na consecução de uma dada atividade. Por exemplo, o esforço feito para ler. O que ambos reiteraram é o posicionamento de Damásio com relação à emoção, considerando-a responsável pela tomada de decisões. 
Quando se fala em motivação, quer-se destacar o sentimento de empolgação por algo realizado. As crianças, por exemplo, desde muito cedo percebem o tipo de receptividade conferida ao que fazem. Quando são valorizadas e agradam, sentem-se mais propensas a prosseguir com a atividade em que se saem bem, de modo usual, sendo o inverso também verdadeiro. Curto et al. (2000, p.83) afirmam que "a motivação está estreitamente relacionada com a auto-estima e o autoconceito acadêmico, e estes são ensinados pelo professor e pelos adultos e crianças que se relacionam com o aprendiz".

\subsection{Aprendizagem, leitura em língua estrangeira (LE) e emprego de estratégias leitoras}

De acordo com Pacheco (2007), a língua materna opera primeiro no desenvolvimento das habilidades de leitura e essas são transferíveis para a língua estrangeira (LE). Entender o quanto essa habilidade leitora na língua materna facilita o aprendizado da leitura em inglês ou qualquer outra língua, vem somar-se ao questionamento para a investigação, através de estudo científico.

Importa mencionar, também, que o inglês é a língua estrangeira focalizada no presente estudo e, por isso, se acrescenta que no processo de aprendizagem de língua estrangeira, seja qual for ela, cada estudante desenvolve suas próprias estratégias, aprimorando-as. Alguns selecionam letras de música e ouvem-nas, repetindo inúmeras vezes a canção, para aumentar a compreensão oral e o vocabulário; ou, ainda, para melhorar a pronúncia e a prosódia; outros assistem a filmes ou, então, organizam grupos de estudo para praticar conversação. Para ler, os estudantes costumam interagir com os demais integrantes do grupo a fim de debater sobre o texto lido, perguntar o significado de alguma expressão ou palavra, discutir o entendimento de um filme legendado em inglês. Como já o declararam O'Malley e Chamot (1990), estratégias são processos, por vezes, selecionados conscientemente pelos aprendizes, podendo originar ações direcionadas ao desenvolvimento do aprendizado da língua alvo, como, de fato, se observa que acontece.

Grigolleto (1990) adita que na leitura em LE podem surgir dificuldades de identificação do código, que, no entanto, são superadas por leitores eficazes, proficientes na língua materna, os quais acabam empregando estratégias que poderiam ter usado em sua língua mãe para atribuir significado às palavras desconhecidas em LE. O fato, porém, é que de uma língua para outra existem situações, palavras e expressões que não têm nada em comum, não coincidem em seus sentidos; tal circunstância pode levar a que, por vezes, no ensino de LE, as explicações dadas ao aprendiz sejam fragmentadas e até inadequadas.

Coracini (1997) afirma que desenvolver uma língua estrangeira é estar em contato com o diferente. A relação com o estranho pode causar medo ou atração e, sobre esses sentimentos a autora afirma que, em ambas as situações, "é o mesmo desejo do outro, desejo de plenitude que move o amor ou o ódio, a aprendizagem ou a resistência a uma determinada língua" (CORACINI, op. cit., p.161). São os dois lados da mesma moeda. A autora se refere a estudos feitos em língua materna (Língua Portuguesa) e estrangeira (Francês e Inglês) em que fica evidente, que as concepções de texto, de leitura, de ensino-aprendizagem que o aluno traz das aulas de língua materna vão influenciar as concepções de texto, leitura e ensino-aprendizagem da LE.

Leitura em LE relaciona-se a construir sentidos, fato que só é possível por meio do histórico vivenciado individualmente, o sujeito e seu conhecimento prévio, que é transformado no momento da leitura. Além de optar por uma metodologia interativa, em termos de leitura, ainda se acrescenta ser indispensável assumir um conceito de linguagem que propicie a 
intersubjetividade, pois a linguagem é uma atividade de interação entre os membros de uma comunidade, "levando ao estabelecimento de vínculos e compromissos anteriormente inexistentes" (KOCH, 1997, p. 9-10).

Conforme Almeida (2002), possível aprender a ler em LE através de diferentes propostas metodológicas e, também por meio de abordagens teóricas completamente antagônicas. Por outro lado, o conhecimento integral de uma língua requer o desenvolvimento das habilidades de audição, conversação, escrita e leitura e isso demanda tempo de estudo. Considerando-se apenas a habilidade de leitura, ela até pode ser razoavelmente bem desenvolvida em um período relativamente curto, variável de acordo com o interesse, o envolvimento e a motivação do aprendiz. Esse aprendizado requer, contudo, aumento do vocabulário, pois a relação entre leitura e vocabulário é bastante direta e traz resultados quase imediatos, sendo posta em prática em situações usuais do dia a dia.

Interessa salientar, ainda, que a extensão e profundidade de conhecimento da língua materna podem influenciar a aprendizagem da LE, por exemplo, pela rapidez de apreensão do input, pela influência de uma variação, tida como livre, pelo valor atribuído à instrução explícita, pela necessidade de evidência negativa, pelo período crítico, pelas diferenças individuais, pelas estratégias de aprendizagem e pelo desenvolvimento do conhecimento metalinguístico. É necessário observar a interferência, na leitura em LE, de fatores como as diferenças de conhecimento prévio, as diferenças no processamento da linguagem e assim por diante (KODA, 1994).

Assim, conforme Oxford (1990) a leitura, tanto em língua materna como em LE, engloba fatores que se estendem desde a interação entre leitor e texto até o processamento cognitivo, ocorrendo em muitos níveis como o fonológico, o sintático, o semântico, o pragmático entre outros. Quando mencionada a questão da leitura em LE comparativamente com a leitura em língua materna, sabe-se que os processos cognitivos ligados à leitura em ambas as línguas são os mesmos. Contudo, existem diversos fatores que caracterizam a leitura em LE como um fenômeno psicolinguístico com qualidades específicas. Similaridade não é identidade. Eis o problema a ser enfrentado. Por exemplo: a etapa inicial - relação fonema/grafema - na língua alvo, no grupo de alunos considerado neste estudo apresenta características diferentes de um grupo de leitores nativos do inglês.

De que modo aferir o quão bem ou mal estão lendo esses alunos é tarefa complicada, já que não se conhece em detalhes a história de leitura de cada indivíduo. Dificuldade, entretanto, não é impossibilidade. De acordo com Grabe (1991), o leitor de uma língua estrangeira normalmente apresenta um vocabulário menor na LE do que na sua língua materna, mesmo que tenha grande conhecimento sintático, e, além disso, pode não estar seguro do conhecimento cultural que é partilhado pelos falantes nativos da língua que está aprendendo.

No caso deste estudo, é indispensável lembrar que o aprendizado de uma nova língua requer o preenchimento de muitos pré-requisitos, conferindo-se importância especial às estratégias de leitura, através das quais podem ser mobilizadas as quatro habilidades linguísticas, uma vez que na perspectiva de Oxford (1990, p.5), "para aprender uma língua é necessário desenvolver [as] quatro habilidades em variados níveis e combinações: escuta, leitura, conversação e escrita". 
Quando se fala em habilidade comunicativa, por sua vez, deve ficar claro que não se está reduzindo o estudo da língua à habilidade de falar, mas incluindo no rol todo um conjunto de fatores: "competência sócio-linguística, competência gramatical, competência do discurso e competência estratégica" (OXFORD, 1990, p.7). Por isso, quando se propõe um trabalho com estratégias de leitura não se está limitando o aprendizado à atividade de ler, mas orientando o uso de estratégias para a obtenção da competência comunicativa, uma vez que sua mobilização ajuda os leitores a participarem ativamente da interação autêntica, espontânea.

\subsection{Compreensão e leitura}

Morais (1996), de sua parte, afirma que para entender a informação textual, cada indivíduo precisa empregar suas próprias competências lexicais, o conhecimento do sentido das palavras, além de captar os processos de análise sintática e de integração semântica. Esse indivíduo precisa mobilizar, também, seu conhecimento do mundo, sua experiência pessoal. Contudo, salienta o autor, todos esses meios e conhecimentos são da mesma forma utilizados no momento em que se entende a linguagem falada, pois as crianças desenvolvem esses processos e conhecimentos, no período anterior, quando ainda não sabiam ler.

O processo de compreensão de um texto vincula-se ao conhecimento que o leitor já detém - seu conhecimento prévio. Nas palavras de Dell'Isola e Peret:

Fatores de compreensão são também provenientes do leitor: a compreensão vai depender, em parte, dos códigos que o leitor maneja, de seus esquemas cognoscitivos, de seu patrimônio cultural e das circunstâncias da leitura (DELL'ISOLA e PERET, 2001, p. 36).

Ao fazer sua leitura, o aprendiz aciona os conhecimentos prévios de que dispõe, seja sobre o mesmo assunto ou sobre algo a ele relacionado, de maneira que possa atribuir significado ao que lê. O conhecimento prévio pode ser, então, usado como um recurso facilitador do entendimento.

O que se sabe é que a compreensão é alcançada quando o leitor lê de forma ativa, podendo antecipar interpretações, identificar significados e expressar dúvidas. Acrescenta-se a decodificação ao processo como sendo uma atividade indispensável, "necessária, mas como instrumento a serviço da compreensão" (CURTO et al., 2000, p.48).

A compreensão, de fato, apenas ocorre quando o leitor consegue responder a suas dúvidas. Para isso, utiliza as estratégias de leitura, um exemplo é o ato de questionar-se e assim obter respostas. Reforça-se novamente a ideia de que aprender a utilizar produtivamente as estratégias de leitura também é uma forma de contribuir para facilitar a compreensão leitora. Segundo Smith (1999, p.107), "a leitura acontece quando fazemos perguntas ao texto escrito e, se obtemos as respostas a essas perguntas, então compreendemos o texto".

\section{METODOLOGIA}

A presente pesquisa apresentou natureza empírica, propondo uma abordagem qualitativa. A coleta de dados foi feita durante as aulas da disciplina de Inglês $V$ e, também, através de atividades realizadas extraclasse. Sua implementação previu a observação sistemática dos aprendizes de língua estrangeira do curso de Letras, Inglês V, de uma universidade do Sul, bem 
como a aferição dos resultados obtidos nos exercícios de compreensão/interpretação textual. Além disso, os próprios exercícios de compreensão/interpretação apresentavam questões focais, perguntas abertas e fechadas, voltadas à análise dos procedimentos e estratégias de leitura, utilizados em cada situação.

O trabalho de investigação - pesquisa de campo - fez a comparação entre o desempenho em leitura de sujeitos que tivessem gosto pelo estudo de inglês como língua estrangeira, e de sujeitos que precisassem aprender inglês, mas não tivessem interesse especial em seu aprendizado. A divisão do grupo foi feita por meio de questionários respondidos em sala de aula e o critério de divisão era o fato de gostarem ou não de inglês.

A proposta foi feita a todo o grupo de alunos da mesma turma, Inglês $V$, de uma universidade do sul. A turma iniciou com 20 alunos, dois desistiram, prosseguindo, então, até o final, 18 alunos. Dos dezoito apenas seis continuaram a participar do trabalho de pesquisa até o seu término, dado que a participação era voluntária.

Os seis participantes que restaram responderam a três questionários e a cinco textos de compreensão e interpretação leitora, durante o decorrer do primeiro semestre de 2008. Alguns materiais foram aplicados em aula, outros, por intermédio da internet. Os questionários, entretanto, foram fornecidos e respondidos, exclusivamente, em sala de aula.

Ao todo, o estudo utilizou como instrumentos de pesquisa, três questionários, especialmente criados para esta investigação, e cinco atividades de leitura, contendo textos e questões de compreensão/interpretação.

A pesquisa foi desenvolvida em diferentes etapas. No mês de abril, o questionário aplicado aos participantes propôs perguntas de caráter mais geral, enfocando o conhecimento, o interesse e os objetivos dos participantes em relação à língua inglesa. Ainda em abril foram trabalhados dois textos com exercícios de compreensão/interpretação, um aplicado durante a aula e o outro, como tarefa de casa.

No mês de maio, foram aplicados um questionário e um exercício de compreensão/interpretação. Ambos abordavam a temática compreensão de leitura em língua estrangeira.

No mês de junho, foram, igualmente, propostas atividades de leitura de textos que objetivavam testar a compreensão/interpretação leitora. Assim, em abril, maio e junho foram desenvolvidas uma ou duas atividades mensais.

Os sujeitos da pesquisa participaram respondendo aos questionários e desenvolvendo as atividades textuais, que foram lidas e acompanhadas pelo pesquisador, pela professora orientadora do trabalho e pelo professor titular da disciplina - Inglês V - que aplicou as atividades, porém não houve nenhuma explicação teórica focada no uso de estratégias.

Para desenvolver todo o estudo, ocorreram seis encontros entre a pesquisadora e os participantes. Todas as atividades que integraram a pesquisa foram distribuídas aos alunos, e, quando retornavam para o professor titular, eram fotocopiadas e analisadas. Posteriormente, foi feita a seleção dos trabalhos que pertenciam às três pessoas que gostavam de inglês, e a três outras, que estudavam inglês por necessidade e não por prazer. Os trabalhos desses seis participantes foram analisados e constituíram a amostra desta investigação. 
Os questionários foram respondidos em aula. As atividades de compreensão leitora -The Sleeping Beauty in the Wood (PERRAULT, 2003), Is Global Warming Harmful to Health? (EPSTEIN, 2000) e Teenagers do Their Talking Online (PALFINI, 2001), foram trabalhados em aula de forma individual, como avaliação. Os textos: A Telephone Call (PARKER, 2008), Is the Party to Whom I Am speaking? (BEITH, 2001) e o Talk is Cheap (HAMILTON e BOWER, 2002) foram enviados aos alunos para serem feitos via internet, a distância. As atividades propostas em sala de aula foram aplicadas pelo professor titular, como tarefa para todo o grupo de alunos.

\section{DISCUSSÃO DOS DADOS}

Delineou-se na investigação o perfil leitor dos participantes, verificando-se as estratégias de leitura empregadas, o entendimento dos textos e a possível relação entre emoção/cognição o gostar ou não da língua estrangeira - inglês. O primeiro, o segundo e o terceiro questionários trouxeram a identificação dos participantes, seus estudos anteriores de inglês e suas atitudes de leitura, focalizando a relação entre cognição/emoção. As atividades e as questões dos testes possibilitaram compreender o emprego das estratégias e seus tipos, o estabelecimento de objetivos de leitura, a compreensão e interpretação de leitura, bem como a receptividade (emoção).

De acordo com as respostas aos questionários, o grupo $A$ apresentava integrantes que gostavam de inglês. Todos os participantes do grupo A eram estudantes de Letras PortuguêsInglês. Eles afirmaram ter acentuado interesse pela língua inglesa e a utilizavam na vida prática, isso é, precisavam dela para atuar no mercado de trabalho, considerando importante aprendê-la. Assim como os participantes do grupo A, os do grupo B cursavam Letras Português-Inglês, porém os estudantes deste grupo preferiam outros idiomas. Apesar de terem uma preferência linguística diferente daquela pela qual optaram, em termos profissionais, reconheciam a importância da língua inglesa enquanto língua 'franca', por ser universal e, também, por causa da exigência do mercado de trabalho. Em seu todo apresentavam um nível de conhecimento e um histórico escolar na rede pública de ensino, frequentando cursinhos. A faixa etária variou de 18 a 40 anos. Quanto à língua inglesa, conseguiam manter uma conversação básica e pequenos diálogos convencionais.

Em relação às atividades textuais aplicadas observou-se o uso de estratégias antes, durante e após a leitura.

Antes da leitura: de início, os leitores inquiridos costumavam analisar o texto inteiro, utilizando uma estratégia direta cognitiva de receber e enviar mensagens, o que lhes permitiu apreender as ideias rapidamente, através de skimming. Eles também observavam a estrutura do texto, cabeçalhos, títulos, subtítulos, estratégia direta de compensação permitindo "adivinhar" inteligentemente, usando dicas e pistas de natureza diversa. Após essa breve análise do texto, levantaram hipóteses, sendo essa uma estratégia direta cognitiva de análise e raciocínio, raciocínio dedutivo. Além disso, pensaram sobre a finalidade ou necessidade de fazer a leitura, estratégia indireta metacognitiva de organização e planejamento do aprendizado através da identificação da finalidade da tarefa.

Durante a leitura, quando não entendiam alguma palavra, os alunos consultavam uma fonte externa, estratégia cognitiva de receber e enviar mensagens, empregando recursos vários como consulta a dicionários e enciclopédias. Formavam, também, imagens mentais de fatos 
mencionados no texto, estratégia direta de memória que mobiliza sons e imagens visuais, táteis, olfativas e gustativas estocadas, usando-as produtivamente. Marcaram (sublinham/circulam) ideias ou palavras importantes para a compreensão - estratégia direta cognitiva que possibilita criar estrutura para input/output - highlight.

Após a leitura: os estudantes avaliavam o quanto tinham entendido do texto, estratégia indireta metacognitiva de avaliar o aprendizado, auto-avaliação. Procuravam, ainda, fazer resumos, estratégia cognitiva de criar estrutura, resumir. Verificavam, por outro lado, se as hipóteses em relação ao contexto tinham se confirmado, estratégia indireta metacognitiva de avaliar a aprendizagem, automonitoramento.

Assim, os seis integrantes do estudo usaram estratégias de leitura. Verificou-se que os estudantes dos dois grupos leram e compreenderam, alguns totalmente, e outros, parcialmente, o texto proposto, com o apoio de estratégias de leitura.

A aplicação das atividades e a subsequente análise das respostas dadas levaram à conclusão de que todos os estudantes consultados estavam conscientes de que usavam estratégias de leitura antes, durante e após terem lido os textos, sendo também sabedores de sua importância para a compreensão leitora. Na verdade, eles as utilizavam de maneira a organizar as informações do texto a ser lido, a atingir os objetivos traçados em relação à leitura e a obter uma maior compreensão. As estratégias, na verdade, facilitaram o entendimento dos textos. Em outras palavras, ler implica utilizar um conjunto de estratégias que resultam na compreensão, quando elas são bem empregadas.

Citando novamente Solé (1998, p.89), a autora postula que algumas "estratégias são passíveis de trocas, e outras estarão presentes antes, durante e depois da leitura". A autora destaca, também, a importância das estratégias de leitura ao longo de toda a atividade leitora, pois elas são ferramentas auxiliares que facilitam o entendimento. E, como já afirmado antes, ler não é uma atividade de mera extração de informações ou de decodificação de palavras. Trata-se de um ato que envolve, inevitavelmente, a compreensão, e que começa a delinear-se antes mesmo da leitura propriamente dita. Um leitor experiente que observe e analise o seu próprio ato de ler, verificará que a decodificação é somente uma das etapas do processo. $O$ ato envolve estratégias como inferir, antecipar e verificar, entre tantas outras. $O$ certo é que as estratégias permitem uma leitura mais rápida e proficiente e o seu uso possibilita apreender melhor o que se lê, permitindo, desse modo, uma escolha consciente das decisões a serem tomadas frente a dúvidas de entendimento.

Tem-se a aditar, ainda, que o exame detalhado das respostas às atividades desenvolvidas neste estudo, evidenciou o emprego de estratégias de leitura, por parte dos alunos, de forma deliberada. Na segunda etapa da análise, foram identificadas e agrupadas as estratégias de leitura empregadas com maior frequência, de acordo com a classificação feita por Oxford (1990). Essas estratégias foram as que se seguem: estratégias diretas cognitivas, estratégias diretas de memória, estratégias diretas de compensação, uma estratégia indireta social e as estratégias indiretas metacognitivas.

A análise feita levou à constatação de mudanças no processo de leitura tal como desenvolvido no período inicial do semestre daquela na parte final, entre os leitores da amostra considerada. Os participantes do estudo aprenderam a usar conscientemente as estratégias de leitura, empregando-as melhor e mais favoravelmente à compreensão dos textos. No início, até 
usavam algumas delas, porém de forma caótica, mais ou menos ao mesmo tempo, sem ter consciência de que o faziam. Ao iniciarem o processo de desenvolvimento da consciência a respeito do seu uso, passaram a identificar a estratégia empregada e a observar o que estavam fazendo, tendo maior cuidado com o processo de leitura.

Segundo Oxford (1990), quanto mais fluente o leitor maior o número e adversidade de estratégias de leitura postas em ação. Como os alunos começaram a considerar as estratégias com mais seriedade e a empregá-las em maior número e diversidade ao longo do semestre acabaram entendendo melhor os textos, ao mesmo tempo em que desenvolveram maior fluência de leitura.

É importante frisar que o processo de leitura depende de diversos fatores: a destreza e a personalidade do leitor, seus objetivos em relação à leitura, o conhecimento prévio do assunto em pauta e o grau de complexidade oferecido pelo texto. As estratégias unem-se a estes fatores como ferramentas que podem auxiliar e desenvolver a aptidão de leitura. Para Solé $(1998$, p.72) "o ensino de estratégias de compreensão contribui para dotar os alunos dos recursos necessários para aprender a aprender".

Outra consideração a fazer é que os aprendizes tidos na amostra deste trabalho foram estimulados a traçar objetivos para sua leitura. Alguns deles já os estabeleciam antes do estudo, outros, no entanto, o fizeram no decorrer do semestre. Se usadas sem objetivos na leitura, as estratégias não teriam surtido o efeito desejado. Por exemplo, elaborar um resumo para ser lido e avaliado pelo grupo é diferente de fazer um resumo para ser lido apenas pelo professor. Conforme Leffa (1996), as estratégias normalmente não têm mérito intrínseco. Seu maior ou menor valor vincula-se diretamente ao objetivo para o qual estão sendo usadas. Sendo assim, as estratégias têm um papel de apoio, quando empregadas em conjunto com os objetivos almejados pelo leitor.

Retornando ao levantamento das respostas dadas, quando os assuntos interessavam aos alunos - tanto no grupo que gostava quanto naquele que não gostava de inglês - eles ficavam motivados e se deixavam envolver pelo texto. A diferença encontrada foi a de que os alunos que gostavam da língua inglesa pareciam envolver-se mais rapidamente e com maior intensidade, achando sempre que o texto era fácil. Na maioria das atividades propostas, os alunos que não gostavam de inglês eram mais facilmente desestimulados, o que os mantinha interessados eram os objetivos imediatos e práticos, precisar de nota, por exemplo. Nas próprias respostas desses estudantes (grupo B), percebeu-se que não gostar da língua já era uma barreira ao aprendizado, talvez devido à falta de entusiasmo e motivação, no entanto, ao estabelecerem um objetivo tentavam vencer as dificuldades e cumprir a tarefa.

Os elementos do grupo A tinham um estímulo real, a emoção positiva, mostrando boa receptividade e interesse natural pelas tarefas, sua execução era gratificante e prazerosa, porém as pessoas do grupo $B$ tinham o objetivo de se formar e esse se tornou um estímulo desafiador. Assim, constatou-se o empenho dos integrantes do Grupo B, que faziam o possível para realizar as tarefas porque queriam se sair bem na disciplina. Para eles, contudo, em alguns momentos, as tarefas tornavam-se penosas. Na visão de Solé (1998, p. 43) para uma pessoa ter um bom desempenho em diferentes atividades de leitura, é importante que perceba que está apto a ler e entender o texto. A autora ressalta a relevância da leitura motivada, aquela leitura "que [fazem] os leitores experientes e que [...] motiva, é a leitura na qual direcionamos, coordenamos: relendo, parando para refletir". 
A motivação e a emoção são fatores que levam o aprendiz a predispor-se favoravelmente e, além disso, a manter-se interessado no que está fazendo. É difícil para um aluno aprender a ler quando, inevitavelmente, o aguarda o insucesso (fracasso), ou quando ele não tem nenhum objetivo, nenhuma finalidade para fazer o que lhe solicitam. Por isso, pode-se assegurar que os aprendizes de inglês que participaram deste trabalho puderam melhorar seu desempenho, pois, se não gostavam de inglês, tinham em mente, ao menos, um objetivo no qual podiam se apoiar, quando enfrentavam dificuldades de entendimento, não ficando paralisados. Por seu turno, os estudantes que gostavam de inglês, além de contar com o fator favorável - predisposição positiva - propunham objetivos que funcionavam, então, como um estímulo adicional.

Os estudantes liam os textos para responder a questões pessoais, investigar problemas encontrados, obter novos conhecimentos, saber uma novidade, conseguir novas informações sobre algo ou sobre alguém. Enfim, são inúmeras as circunstâncias motivadoras que os levaram a buscar a leitura, mas todas se vinculam a um desejo, a uma emoção. Segundo Curto et al. (2000, p.83), na certa "precisamos nos sentir pessoalmente envolvidos, isto é, sentir que a tarefa tem a ver com nossos próprios desejos e objetivos".

É relevante neste ponto destacar a inter-relação entre cognição e memória no processamento cognitivo e também na análise proposta por este estudo. Assim, enquanto os alunos investigados liam os textos, realizavam as atividades propostas e mobilizavam estratégias de leitura, ao mesmo tempo processavam cognitivamente o texto e ativavam a memória. De modo similar, no momento em que os aprendizes apreendiam informações ou marcavam o texto, efetuavam operações que lhes conferiam a direção e o controle sobre a leitura. Em caso de dúvida, focalizavam a atenção, e, no momento em que a dúvida era sanada, prosseguiam.

Ainda sobre cognição e memória, vale repetir que, enquanto a leitura estava sendo feita eram acionadas várias ações na mente do leitor, as quais o auxiliam a compreender e interpretar o texto. As ações referidas são as próprias estratégias de leitura e, inúmeras vezes, são tão automáticas que, usualmente, não se questiona a respeito delas ou do seu uso. Elas acontecem durante o desenvolvimento da leitura, tendo a possibilidade de se modificar ou de se manter. Assim, ao ler um texto, a mente de cada sujeito seleciona a ação cognitiva ou social que lhe parece melhor para produzir inferências que lhe permitam complementar o que é dito pelo texto.

Nesta pesquisa, quando os aprendizes recorriam ao conhecimento prévio estavam acionando a memória ao mesmo tempo em que o processamento cognitivo ia se desenrolando através da leitura. Os conhecimentos mobilizados integravam as recordações de vivências anteriores, inclusive a lembrança de leituras realizadas em outras ocasiões.

No momento em que os participantes do estudo usavam as estratégias de seleção, o cérebro identificava aquilo que cada aprendiz já conhecia, pois através dessas estratégias, o cérebro reconhece quando não necessita focalizar determinadas letras, ou passagens textuais, de vez que já conhece as letras ou palavras subsequentes. Koch (2008) comenta que ao ler, o indivíduo adapta ao texto um modelo cognitivo, ou esquema já existente, fundamentado em conhecimentos armazenados na memória. O esquema inicial pode, durante a leitura, se confirmar e se fazer mais preciso, ou pode, ainda, se modificar rapidamente de acordo com a necessidade do leitor.

Desse modo, os aprendizes se propunham a ler e compreender o que liam para realizar as atividades propostas. Ao receber os textos, de imediato recorriam ao uso de estratégias para entender a solicitação, usando-as para entender melhor o texto. Então, "ler é compreender um 
texto. [E] Compreender é um ato cognitivo, ou seja, o resultado de uma atividade mental" (Curto et al., 2000, p. 47).

Sobre a influência da emoção na compreensão em leitura, tanto em língua materna quanto em língua estrangeira, Oxford (1990) observa que nem todos os alunos que têm bom desempenho comunicativo são desinibidos. Estudantes ansiosos, muitos deles excelentes aprendizes, são, de modo geral, tímidos, combatendo a emoção negativa com o emprego de algumas técnicas simples como conversar consigo mesmos, pensando positivamente e transformando uma atitude em uma estratégia. Nesses casos, a emoção positiva passa a ser usada como uma ferramenta para a melhoria de desempenho, já que o artifício pode facilitar a leitura, por exemplo, dando-lhes maior segurança. A atitude se tornará, em vista disso, uma estratégia facilitadora. Por esses e outros motivos, é essencial que além do papel estratégico da emoção se conheça, também, a relevância do uso de outras estratégias no processamento da leitura.

Complementarmente, o emprego de estratégias de leitura facilita e auxilia o leitor a entender o texto, tanto na leitura em língua materna como em língua estrangeira. $O$ aprendiz que estuda um texto pode não ter consciência de que está usando alguma forma de relacionar-se cognitivamente com ele, mas sempre está. De acordo com Kato (2002), há processos de várias naturezas envolvidos no ato de ler devido à multiplicidade de estratégias que os leitores utilizam de modo habitual.

\section{CONSIDERAÇÕES FINAIS}

A proposição de atividades de leitura requer que o professor faça uso de estratégias de leitura e que planeje objetivos de leitura claros, previamente estabelecidos, para que o leitor entenda o que está sendo requerido fazer com um dado texto, pois não há um único modo de ler. Cada texto demanda um procedimento de leitura adequado à meta que o leitor tem em mente. Se ele não tiver propósito algum, sua leitura padecerá de falta de rumo. Além disso, ler é entender; pois sem compreensão não há leitura. Compreender um texto é ter acesso a uma das interpretações que ele autoriza, é buscar um dos sentidos por ele possibilitados. A possibilidade existente decorre exatamente da bagagem sociocultural do leitor (DELL'ISOLA e PERET, 2001).

As atividades propostas neste estudo indicaram haver procedimentos de leitura diversos, de acordo com a predisposição emocional do leitor, e através deles foi possível identificar e analisar o emprego de estratégias de leitura por seis aprendizes universitários, da disciplina de Inglês $\mathrm{V}$, como língua estrangeira, bem como observar as mudanças que esses seis sujeitos apresentaram, ao longo do semestre, ficando suficientemente claro que houve desenvolvimento de sua habilidade de leitura no decorrer do estudo.

Desse modo, mesmo não tendo qualquer pretensão a generalizações demasiado amplas, não há como desconhecer que aliar emoção e cognição para entender melhor como se dá o entendimento textual, é uma necessidade e não uma veleidade. Em que pese à modéstia da contribuição, ela é importante por indicar rumos para futuras pesquisas.

Assim, através deste estudo foi possível concluir que a emoção e as estratégias de leitura são fatores intensamente atuantes na atividade leitora. Os resultados obtidos apontaram os procedimentos de leitura mais usuais e as estratégias de leitura mais mobilizadas, correlacionandoos à emoção positiva ou negativa, como fator condicionador dos resultados finais. 


\section{REFERÊNCIAS BIBLIOGRÁFICAS}

1. ALMEIDA, R. Q. de. As palavras mais comuns da língua inglesa. São Paulo: Novatec, 2002.

2. BEITH, M. Is This the Party to Whom I Am Speaking? Newsweek International, August 2001. Disponível em: <http://www.accessmylibrary.com/coms2/summary_0286-27083941_ITM>. Acesso em: 5 março 2008.

3. COLOMER, T., CAMPS, A. Ensinar a ler, ensinar a compreender. Trad. Fátima Murad. Porto Alegre: Artmed, 2002.

4. CORACINI, M. J. Língua estrangeira e língua materna: uma questão de sujeito e de identidade. Letras e Letras. Uberlândia, MG. v.14, n.1, p. 153-169, 1997.

5. CURTO, M. L., MORILLO, M. M., TEIXIDÓ, M. M. Escrever e ler: como as crianças aprendem e como o professor pode ensiná-las a escrever e a ler. Porto Alegre: Artes Médicas, 2000.

6. DAMÁSIO, A. R. O erro de Descartes. São Paulo: Companhia das Letras, 1996.

7. . O mistério da consciência. São Paulo: Companhia das Letras, 2000.

8. DELL'ISOLA, R., PERET, L. Leitura: inferências e contexto sociocultural. Belo Horizonte: Formato Editorial, 2001.

9. DÖRNYEI, Z., SKEHAN, P. Individual differences in second language learning. In: DOUGHTY, C. J., LONG, M. H. The handbook of second language acquisition. Oxford: Blackwell Publishing, 2003.

10. EPSTEIN, P. R. Is Global Warming Harmful to Health? Scientific American, August 2000. Disponível em: <http://chge.med.harvard.edu/about/faculty/ journals/sciam.pdf>. Acesso em: 10 março 2008.

11. FRIDJA, N. H., MANSTEAD, A., BEM, S. Emotions and Beliefs. How Feelings Influence Thougts. Maison des Sciences de I'Homme. Cambridge: University. GRABE, W. Current developments in second language reading research. TESOL Quarterly, v.25, n.3, p.375-406, 1991.

12. GRIGOLLETO, M. A influência da previsibilidade sobre as estratégias de compreensão na leitura em LM e LE. Trabalhos em Lingüística Aplicada v.15, p.25-47, 1990.

13. HAMILTON, A., BOWER, A. Talk Is Cheap. Times, Best of The Rest, August 09, 2002. Disponível em: <http://www.time.com/time/magazine/ 09, 2002. Disponível em: <http://www.time.com/time/magazine/article/0,9171, 183961 -4,00.html>. Acesso em: 24 fevereiro 2008.

14. KATO, M. A. No mundo da escrita uma perspectiva psicolingüística. São Paulo: Editora Ática, 2002.

15. KLEIMAN, A. Texto e leitor: aspectos cognitivos da leitura. Campinas: Pontes, 2004.

16. . Leitura: ensino e pesquisa. São Paulo: Pontes, 1996.

17. KOCH, I. V. Desvendando os segredos do texto. São Paulo: Cortez, 2008.

18. A atividade de produção textual. In: $\mathrm{KOCH}$, Ingedore Villaça. O texto e a construção dos sentidos. São Paulo: Contexto, 1997, p.11-20.

19. KODA, K. The effects of lower-level processing skills in FL reading performance: implications for instruction. The Modern Language Journal, v.76, n.4, p.502-512, 1994. 
20. LEFFA, V. J. Aspectos de leitura. Porto Alegre: Sagra - DC. Luzzatto, 1996.

21. MARCUSCHI, L. A. Leitura e compreensão de texto falado e o escrito como ato individual de PR ática social. In: ZILBERMAN, R., SILVA, E. Leitura: perspectivas interdisciplinares. São Paulo: Ática, 2005.

22. MATURANA, H. Emoções e linguagem na educação e na política. Belo Horizonte: UFMG, 2005.

23. MORAIS, J. A arte de ler. São Paulo: Editora UNESP, 1996.

24. NUNES, M. B. Redescobrindo o papel do professor de leitura em língua estrangeira. In: CELANI, M. A. A. (org.) Ensino de Segunda Língua: Redescobrindo as Origens. EDUC, 2000, p. 107-132.

25. O'MALLEY, J. M., CHAMOT, A. U. Learning strategies in second language acquisition. New York: Cambridge University Press, 1990.

26. OXFORD, R. L. Language learning strategies: what every teacher should know. Boston: Heinle \& Heinle Publishers, 1990.

27. PACHECO, R. L. A competência em leitura em L1 e a consciência linguística em L2 como facilitadoras da compreensão leitora em L2. 2007. 179f. Dissertação (Programa de PósGraduação em Letras- Mestrado) Universidade de Santa Cruz do Sul, 2007.

28. PALFINI, J. Teenagers do Their Talking Online. PCWorld, June 21, 2001. Disponível em: <http://www.pcworld.com/article/53444/teenagers_do_theirtalking_online.html>.Acesso em: 20 março 2008.

29. PARKER, D. A Telephone Call. American literature. Disponível em: <http://www.americanliterature.com/Parker/SS/ATelephoneCall.html>. Acesso em: 20 fevereiro 2008.

30. PERRAULT, C. The Sleeping Beauty in the Wood, 2003. Disponível em: < http://www.pitt.edu/ dash/perrault01.html>. Acesso em: 24 março 2008.

31. SMITH, F. Leitura significativa. Porto Alegre: Artes Médicas, 1999.

32. SOLÉ, I. Estratégias de leitura. Porto Alegre: Artes Médicas, 1998. 